\title{
Uranium Metabolism Associated with Ontogenetic Growth of Birds-Case Studies with Broilers and Ducks
}

\author{
Joao Dias de Toledo Arruda-Neto ${ }^{1,2}$, Guacyara Tenorio Cavalcante ${ }^{1}$, \\ Guilherme de Paula Nogueira ${ }^{3}$, Tulio Eduardo Rodrigues' ${ }^{1}$, Luiz Eduardo Correa Fonseca ${ }^{3}$, \\ Mitiko Saiki4, Godofredo Camara Genofre ${ }^{2,5}$ \\ ${ }^{1}$ Physics Institute, University of São Paulo, São Paulo, Brazil \\ ${ }^{2}$ CEPESq/Uniĺtalo-Italy-Brazilian University Center, São Paulo, Brazil \\ ${ }^{3}$ School of Veterinary Medicine, São Paulo State University/UNESP, Araçatuba, Brazil \\ ${ }^{4}$ Institute for Energy and Nuclear Research, IPEN/CNEN-SP, São Paulo, Brazil \\ ${ }^{5}$ Institute for Biomedical Sciences, University of São Paulo, São Paulo, Brazil \\ Email: arruda@if.usp.br
}

Received 2 June 2014; revised 16 July 2014; accepted 8 August 2014

Copyright (C) 2014 by authors and Scientific Research Publishing Inc.

This work is licensed under the Creative Commons Attribution International License (CC BY).

http://creativecommons.org/licenses/by/4.0/

c) (i) Open Access

\begin{abstract}
Cobb broilers and domestic ducks, both one-day-old, were treated using ration doped with $20 \mathrm{ppm}$ of uranyl nitrate. Uranium concentrations in the tibia ( $\mu \mathrm{g}-\mathrm{U} / \mathrm{g}$-bone) were measured by neutron activation analysis as function of the animals' age, from the neonatal period to maturity. Results show that Uranium and Calcium qualitatively follow the same metabolic pathway, and that adult ducks incorporate on average ten times more Uranium than broilers. Data interpretation shows that the Uranium clearance rate in broilers is substantially higher than that in ducks, suggesting that metabolic characteristics favoring Calcium retention in bone may hinder the elimination of Uranium in ducks. The need for further comparative biochemistry studies between Galliformes and Anseriformes is addressed.
\end{abstract}

\section{Keywords}

Cobb Broilers, Domestic Ducks, Uranium-Doped-Ration, Uranium-Content in Bones, U/Ca Metabolism, Uranium Residence Times

\section{Introduction}

Uranium, as well as strontium is usually classified as a "familiar element", as a result of the existence of readily

How to cite this paper: Arruda-Neto, J.D.T., et al. (2014) Uranium Metabolism Associated with Ontogenetic Growth of Birds-Case Studies with Broilers and Ducks. Advances in Bioscience and Biotechnology, 5, 768-776. 
available natural sources. The interest in uranium metabolism stems from the fact that it is a ubiquitous and a potentially hazardous contaminant although it is a non-essential element. Since uranium is a trace constituent of rock phosphate, it is present in fertilizers and livestock feed supplements. Despite dicalcium phosphate presents concentrations of uranium as high as $200 \mathrm{ppm}$ [1], it is extensively used in broilers diet [2]-[4].

Following uptake through the gastrointestinal tract, uranium is mostly deposited in the skeleton. In fact, bone is one of the most important biological accumulators of uranium [5]. It would appear that $\mathrm{Ca}^{++}$and uranyl ions $\mathrm{UO}_{2}{ }^{++}$follow the same metabolic path. It has been argued that the uranyl ion apparently exchanges with $\mathrm{Ca}^{++}$at the surfaces of bone mineral crystals, the distribution of uranium among different bones and bone parts being similar to that of calcium, and uranium becomes diffusely distributed in bone volume. Movement of calcium in and out of bone is mediated by several distinct processes in which it may be presumed that uranium also participates. The nature of these processes is such that the residence time of an atom of uranium or other bone seeking element in bone can be a substantial fraction of a lifetime. The matter of uranium was also addressed before in the ICRP Publication 69 (1995) [6].

Although it is commonly said that uranium mimics calcium [7] [8], whether $U$ and Ca qualitatively follow the same metabolic pathway, or if there are quantitative differences in how the body process these two elements has not been investigated as yet.

As in the case of other metals such as $\mathrm{Cd}, \mathrm{Pb}, \mathrm{Si}, \mathrm{Sr}$, etc. for example, uranium is also subject to stochastic processes of loss from circulation via excretion, redeposition in bone, or soft tissue uptake [6]. The latter usually accounts for only a small fraction of the loss out of the circulation. However, from a radiological viewpoint it may constitute a significant fact for consumers of poultry meat and products.

\subsection{Uranium Metabolism in Birds-Preliminary Observations in Broilers}

More recently, a preliminary experiment with Cobb broilers was carried out at this Laboratory, starting with seven-day-old birds fed with ration doped with uranyl nitrate up to adulthood [9]. Uranium concentration in the tibia was measured by neutron activation analysis. Quite surprisingly, results showed that the concentration of uranium ( $\mu \mathrm{g}-\mathrm{U} / \mathrm{g}$-bone) decreased along the animal life period, at variance with results from mammals for example, meaning that the skeleton of broilers grows at a faster rate than the corresponding accumulation of uranium. This finding was tentatively interpreted as an interplay between two metabolic peculiarities, associated both with U transfer (uptake), and U removal (clearance) from the bones. A counter-case study to prove this hypothesis would be the performing of a similar experiment with a bird exhibiting rather distinct metabolic characteristics, thus "favoring" retention of $U$ and reducing the clearance rate as a consequence.

\subsection{Metabolic Characteristics of Broilers and Ducks}

A quite informative article dealing with respiratory, circulatory and metabolic aspects of Tufted Ducks was published almost three decades ago [10]. The correlation of basal rate of metabolism with several factors was worked out in birds by McNab [11] with conclusions still valid nowadays. In the same vein, it was concluded elsewhere that the principal source of variation in avian basal rates, other than body mass, is taxonomic affiliation [12].

In ducks, for instance, the hemoglobin affinity for oxygen allows rapid adjustments of oxygen binding and release since the process is far less demanding in energy than an increase in cardiac output. This adaptation has been attributed to changes in the primary structure of globin chains, modulating oxygen uptake and delivery to the tissues [13] [14]. Moreover, metabolic demand of migratory birds, as in ducks, is associated with intense muscular activity performed during flight; thus, enormous muscle activity requires a large storage of calcium $\left(\mathrm{Ca}^{++}\right)$as a key element in order to maintain the necessary demand of fast and intense muscle contractions. Whatsmore, ducks have a predisposition for storing calcium (primarily in the bones, as the main source of the element) to be used over long periods of time, such as migratory flight. Such metabolic peculiarity might be conserved in domestic ducks. Additionally, there must be mechanisms most likely minimizing the loss of bone calcium to ensure calcium supply during shortages of calcium sources, in a way that is more effectively than in birds not subject to the same demand.

\subsection{The Goal and the Rationale of This Work}

Information and reasoning led us to conjecture that the uranyl $\left(\mathrm{UO}_{2}^{++}\right)$, following the pathway of calcium meta- 
bolism, would be stored in larger quantities in ducks, due to a metabolic and genetic susceptibility associated with the group.

Since ontogenetic development is fuelled by metabolism, a decision was made to perform a detailed measurement of uranium concentrations in bones of broilers and wild ducks fed with uranyl nitrate doped ration, through a period of time starting from the first day of the animal's life through to the completion of its ontogenetic growth.

In this sense, this experiment would, for the first time, allow the sensing of information on the pathway characteristics of $U$ in birds with different metabolic characteristics, such as broilers and ducks. This is a rather sensitive issue given the corresponding radiobiological implications to the animals and to their consumers.

\section{Materials and Methods}

\subsection{Animals}

Around seventy one-day-old Cobb broilers and seventy one-day-old domestic ducks (Common Name: DuckPeking) were housed in 06 boxes $1.5 \times 3.0=4.5 \mathrm{~m}^{2}$ with wood shavings as bedding, and in each box there were 23 animals, The animals were fed ad libitum in infant tubular feeders with a capacity of $5.0 \mathrm{~kg}$ during the first 10 days; after this period specific tubular feeders for broiler, with a capacity of $30 \mathrm{~kg}$, were used. The water was initially provided in infant drinkers with a capacity of 3 liters, which were later replaced by bell drinkers.

The animals were separated into two groups, each receiving the following food supplements:

Group-1 (control animals-broilers and ducks): basic food with specific formulation for each of the birds and for each distinct life period, following commercial procedures, was supplied and monitored (see Table 1).

\section{Table 1. Percent composition and calculated values of starter and growing diets (according to [15]).}

\begin{tabular}{|c|c|c|c|c|}
\hline Ingredients (\%) & Broiler Starter (1 - 21 days) & Broiler Growing (22 - 42 days) & Ducks Starter & Ducks growing \\
\hline Maize, ground & 60.089 & 63.079 & 56.847 & 76.735 \\
\hline Soybean meal & 26.517 & 25.429 & 31.863 & 16.576 \\
\hline Soybean oil & 2.136 & 3.561 & 1.154 & \\
\hline Meat and bone meal & 9.05 & 6.742 & 6.452 & 4.839 \\
\hline Limestone & 0.064 & 0.294 & & 0.195 \\
\hline Salt & 0.350 & 0.360 & 0.350 & 0.350 \\
\hline Vitamin premix $^{1}$ & 0.100 & 0.100 & 0.1 & 0.1 \\
\hline Micromineral premix ${ }^{2}$ & 0.100 & 0.100 & 0.1 & 0.1 \\
\hline DL-Methionine & 0.203 & 0.176 & 0.026 & 0.015 \\
\hline L-Lysine HCL & 0.142 & 0.122 & & \\
\hline Kaolin-inert & 1.249 & 0.037 & 3.108 & 1.090 \\
\hline Total & 100 & 100 & 100 & 100 \\
\hline \multicolumn{5}{|l|}{ Calculated composition } \\
\hline ME (kcal/kg) & 3054.064 & 3163.120 & 2901.283 & 3087.408 \\
\hline Crude Protein (\%) & 21.25 & 19.939 & 22.016 & 16.009 \\
\hline Methionine + Cistine (\%) & 0.844 & 0.791 & 0.700 & 0.55 \\
\hline Lysine (\%) & 1.189 & 1.099 & 1.160 & 0.749 \\
\hline Calcium (\%) & 0.971 & 0.837 & 0.709 & 0.60 \\
\hline Available phosphorus (\%) & 0.545 & 0.43 & 0.422 & 0.331 \\
\hline
\end{tabular}

${ }^{1}$ NUTREMIX-(Vitamin premix). Composition per kg of product: Initial: Vit.A, 10,500.00 UI; Vit.D3, 2,500,000.00 UI; Vit.E, 15.000 mg; Vit.K3, 12.500 mg; Vit.B12, 19.000 mcg; Vit.B1, 1000 mg; Vit.B2, 7500 mg; Piridoxine 1250 mg; Biotine, 100 mg; Folic acid, 450 mg; Pantotenic acid, 9500 mg; Niacin, 40.000 mg; Antioxidant, 50 mg. Growing: Vit.A, 9,000.00 UI; VitD3, 2,000,000.00 UI; Vit.E, 10.000 mg; Vit.K3, 10.500 mg; Vit.B12, 18.000 mcg; Vit.B1, 800 mg; Vit.B2, 6000 mg; Piridoxine 1000 mg; Biotine, 80 mg; Folic acid, 400 mg; Pantotenic acid, 8000 mg; Niacin, $37.000 \mathrm{mg}$; Antioxidant, $50 \mathrm{mg}$. 
Group-2 (doped animals-broilers and ducks): the same basic food of Group-1 but doped with 20 ppm of uranyl nitrate, from now on referred to as U-doped food.

Feeding (as well as water) was monitored and average accumulated consumptions were estimated. The animals were tagged with individual rings and weighed weekly and afterwards sacrificed. The animals were also clinically checked throughout experiment duration.

Starting with two-day-old birds, two animals per group were euthanized at the following sequence of ages (in days):

Ducks (control and doped animals) - 2, 7, 9 and 15. After the 15th day the animals were sacrificed at intervals of 6 or 7 days, i.e., from the 15th to the 78th day.

Broilers-from 2 to 14-day-old doped animals at intervals of one day (2, 4, 6, 8, and 10-day-old for the control), and from 14 to 70 at intervals of 6 or 7 days (control and doped animals).

Three one-day-old ducks and broilers were sacrificed for the purpose of obtaining base values, that is, residual uranium transferred to the animals during the pre- and neonatal phases.

The animals were euthanized according to the Guide of Care and Use of Experimental Animals (Canadian Council on Animal Care, vol. 2, 1984), receiving adequate care with appropriate veterinary supervision. The tibiae were immediately removed and frozen at $-20^{\circ} \mathrm{C}$ for a posteriori processing and analysis.

\subsection{Sample Preparation}

The bones were individualized in porcelain melting pots, weighed and maintained for 12 hours inside an oven at $120^{\circ} \mathrm{C}$ leading to water evaporation. Next, the material was kept on a hot plate at $180^{\circ} \mathrm{C}$ for 8 hours for carbonization. After this, the melting pots were inserted into an oven at $600^{\circ} \mathrm{C}$ until conversion of the material into ashes, diluted into $2 \%$ nitric acid.

Approximately $100 \mathrm{mg}$ of bone ash solutions from each animal was weighed and sealed in polyethylene involucres. Standard aliquots of $U$ and Ca solutions, with exact known concentrations, were pipetted onto $2 \mathrm{~cm}^{2}$ pieces of Whatman $n^{\circ} .40$ filter paper and dried in a dessicator. Sets constituted by bone samples and standards were irradiated in the IPEN research nuclear reactor (IEA-R1, 2MW) for $8 \mathrm{~h}$ at a thermal neutron flux of approximately $10^{12} \mathrm{n} \cdot \mathrm{cm}^{-2} \cdot \mathrm{s}^{-1}$.

A solution of the reference bone sample IAEA-A12 was also prepared, so as to check the analytical accuracy of the method.

Additionally, three samples of ration (food) diluted with $2 \%$ nitric acid were similarly analyzed to determine their possible residual Uranium content.

\subsection{Data Taking}

\subsubsection{Uranium}

Samples of bones, ration and standards, all in triplicate, were analyzed by means of conventional gamma-spectrometry procedures [16] [17], using a high resolution $75 \mathrm{~cm}^{3}$ - high purity Ge detector operated with a 671 ORTEC amplifier in pile-up rejection mode. For the quantification of uranium 2 hour counting runs were used, thus allowing the determination of the three main gamma lines following the decay of ${ }^{239} \mathrm{~Np}$ (formed from ${ }^{238} \mathrm{U}$ $\left.+\mathrm{n} \rightarrow{ }^{239} \mathrm{U} \rightarrow{ }^{239} \mathrm{~Np}\right): 106 \mathrm{keV}, 228 \mathrm{keV}$ and $278 \mathrm{keV}$.

\subsubsection{Calcium}

About $150 \mathrm{mg}$ of bone samples, weighed and heat-sealed in polyethylene bags, were irradiated at the IEA-R1 nuclear reactor together of synthetic standards of Ca. The Ca standard was previously prepared by pipetting a known aliquot of Ca standard solution provided from SpexCertiprep Chemical (USA) onto a sheet of Whatman No. 40 filter paper. The amount of Ca used was $1000 \mu \mathrm{g}$. After drying at room temperature in a dessicator, the filter sheets were placed in clean polyethylene bags, and irradiated for sixteen hours under thermal neutron fluxes of about $10^{12} \mathrm{n} \cdot \mathrm{cm}^{-2} \cdot \mathrm{s}^{-1}$. Following an adequate decay time of one week, the irradiated samples and Ca standard were measured using an HPGe detector (Model GX2020) coupled to an integrated signal processor (Model 1510), both from Canberra. The resolution (FWHM) of the system was $0.90 \mathrm{keV}$ for the $122 \mathrm{keV}$ gamma-ray peak of ${ }^{57} \mathrm{Co}$ and $1.87 \mathrm{keV}$ for the $1332 \mathrm{keV}$ gamma-ray of ${ }^{60} \mathrm{Co}$. Calcium was identified by measuring the ${ }^{47} \mathrm{Ca}$ gamma lines of 159.38 and $1297.09 \mathrm{keV}$ and half life of $4.54 \mathrm{~d}$. The elemental concentration was calculated by comparative method. 


\subsection{Statistical Evaluation}

It should be emphasized that each data point corresponds to an average taken over the 3 gamma ray decay lines of ${ }^{239} \mathrm{~Np}$ measured in samples of two animals; therefore it is the average of 6 experimental values for uranium concentrations. All error bars showing up in the figures represent external standard deviations. In reality, since data averaging was the only data handling procedure, calculation of external standard deviations of the averaged values was carried out, simply a conventional parametric statistics in the normal model [18]. Because of the one to two orders of magnitude difference between Uranium concentrations in bones of broilers and ducks, it would seem rather redundant applying statistical tests as e.g. Tukey's or ANOVA.

\section{Results}

There were transitory treatment effects $(P<0.05)$ in body weight change; attributed to the normal fluctuations in weight within any group of birds and therefore not considered biologically significant or U-induced.

Measurement of uranium concentrations in the ration samples provided an average of $0.28 \pm 0.03 \mathrm{ppm}$. Uranium concentrations in bones of control animals up to 14-day-old were $0.04 \pm 0.02 \mathrm{ppm}$ and $0.12 \pm 0.5 \mathrm{ppm}$, for broilers and ducks respectively, and $0.03 \pm 0.01 \mathrm{ppm}$ and $0.15 \pm 0.6 \mathrm{ppm}$ for 14-day-older broilers and ducks respectively.

In fact, Uranium concentrations measured in control animals were low, from one to two orders of magnitude smaller than the concentrations in the animals fed with uranyl nitrate. This is additional evidence that commercially available ration used contains low levels of uranium as well.

Results for the concentrations of Uranium in bones of broilers and ducks, as function of age, expressed as micrograms of $U$ per gram of bone (wet samples), represented by $\mathrm{C}(\mu \mathrm{g}$-U/g-bone) are shown in Figure 1, while the insert in Figure 1 displays results for the fraction of calcium in bones of broilers, expressed as $\mathrm{mg}-\mathrm{Ca} / \mathrm{mg}$ bone. Within experimental uncertainties, this calcium data set is a flat and structureless function of the animal age, averaging at $0.25 \pm 0.04$ (mg-Ca/mg-bone) or $(25 \pm 4) \%$ in the whole age interval. Results for calcium in ducks (not shown) behave similarly, except that the average fraction is higher: $0.38 \pm 0.05$ (mg-Ca/mg-bone), or $(38 \pm 5) \%$.

Results for the restricted life period of 1 - 14 days (neonatal and very young animals) are shown in Figure 2, and plotted in the insert is the ratio C(ducks)/C(broilers), where C(ducks) and C(broilers) are the concentrations of Uranium in bones of ducks and broilers respectively (the horizontal lines in the insert represent average quantities at the corresponding age-interval).

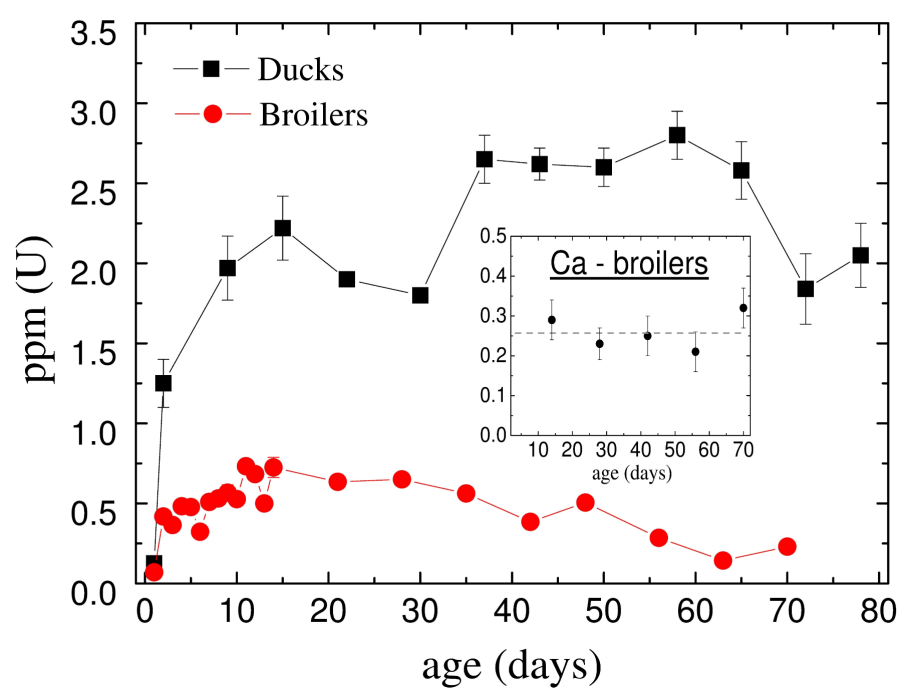

Figure 1. It shows results for the concentrations of Uranium in bones of broilers and ducks, as function of age, expressed as micrograms of $\mathrm{U}$ per gram of bone (wet samples), represented by $\mathrm{C}(\mu \mathrm{g}-\mathrm{U} / \mathrm{g}$-bone). Insert: results for the fraction of calcium in bones of broilers, expressed as mg-Ca/mg-bone. 


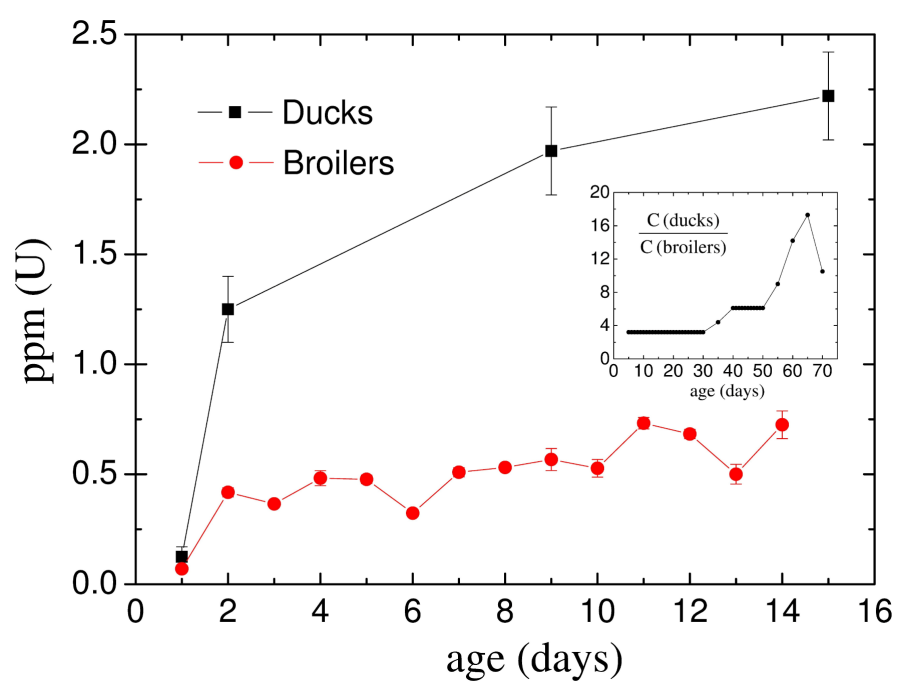

Figure 2. Results for the restricted life period of 1 - 15 days (neonatal and very young animals). Insert: ratio C(ducks)/C(broilers), where C(ducks) and C(broilers) are the concentrations of Uranium in bones of ducks and broilers, respectively. The horizontal lines represent average quantities of the corresponding age-interval.

\section{Discussion}

\subsection{Concentration of Uranium-Deepening of Its Meaning}

The experimental results obtained in this work (incorporation of Uranium in bones) are expressed in terms of concentration of Uranium, a quantity defined by

$$
C_{\mathrm{U}}=m_{\mathrm{U}} / m_{\text {bone }}
$$

where $m_{\mathrm{U}}$ is the mass of Uranium measured in a bone sample with mass $m_{\text {bone. }}$. This being a normalized quantity, that is, it expresses the amount of Uranium mass per bone mass unit. In our case it is micrograms of Uranium ( $\mu \mathrm{g}-\mathrm{U}$ ) per milligram of bone (mg-bone), which is equivalent to parts per million of Uranium (ppm-U).

The concentrations of Uranium in bones of broilers and ducks were measured as function of age, spanning a life period from birth to maturity, that is, from the early stages of skeleton development. It is noted that,

a) when $C_{\mathrm{U}}$ is constant, or slowly varying with time, it means that the incorporation of $U$ increases at a rate similar to skeleton growth rate. In other words, $m_{U}$ and $m_{\text {bone }}$ (see Equation (1)) are directly proportional quantities;

b) when $C_{\mathrm{U}}$ increases (decreases) with time, it means that the $\mathrm{U}$ incorporation rate is higher (smaller) than skeletal growth rate.

The present results (Figure 1 and Figure 2) are discussed by splitting the life period of the animals into life-period-1 (from 1 to 20-day-old) and life-period-2 (20-day-older). Uptake of Uranium is fairly distinct in these two life periods. In fact, it is very likely that young animals (life-period-1) are often in positive uranium balance (between uptake and excretion) due to a build up of uranium in the growing skeleton, vis-à-vis older animals (life-period-2) [5].

\subsection{Life-Period-1: Earlier Life Stages-Rapidly Growing Skeleton}

Broilers-The concentrations of Uranium $\left(C_{\mathrm{U}}\right)$ in bone of neonatal and young broilers are nearly constant and/or slowly varying with time in life-period-1, as shown in Figure 2 (full circles points). Therefore (see Equation (1)) $C_{U}=m_{U} / m_{\text {bone }} \approx k$ (constant), indicating that the amount of $U$ incorporated and the skeleton (bones) mass of younger broilers increases at the same rate. This is what happens with Calcium in bones too as clearly indicated in Figure 1-insert, where it is plotted concentrations of Calcium in bone, that is, $C_{\mathrm{Ca}}=m_{\mathrm{Ca}} / m_{\text {bone }} \approx k^{\prime}$ (constant). Therefore, the masses of both Uranium and Calcium measured in bone increases proportionally to the skeleton mass, suggesting that $\mathrm{U}$ and $\mathrm{Ca}$ follow the same metabolic pathway at least for neonatal and young 
broilers. Overall, this is compelling evidence for the Uranium Calcium-mimicry hypothesis.

Ducks-A simple visual inspection of Figure 1 reveals that ducks have a strong affinity for Uranium, and that such affinity is quantitatively quite distinct according to the life period. In the case of neonatal and young ducks, life-period-1 (Figure 2), Uranium concentration appreciably increases with time, for instance, nearly duplicating from $t=2 \mathrm{~d}, 1.25$ ( $\mu \mathrm{g}$-U/g-bone), to $t=15 \mathrm{~d}, 2.25$ ( $\mu \mathrm{g}$-U/g-bone). It seems that the uptake biokinetics in ducks in early life stage is more avid for Uranium compared to Calcium.

Overall, ducks incorporate three times more Uranium than broilers do in life-period-1 (see Figure 2). This result is consistent with the higher predisposition of ducks to store Calcium in bones, as discussed in the introduction and in accordance with our results: $0.25 \pm 0.04$ and $0.38 \pm 0.05$ (mg-Ca/mg-bone) for broilers and ducks respectively.

\subsection{Life-Period-2: Young to Mature Animals}

Broilers-The Uranium concentration $\left(C_{\mathrm{U}}\right)$ in bones of broilers 20-day-older decreases all along life-period-2 (Figure 1). It is known from Equation (1) that $C_{U}=m_{U} / m_{\text {bone }}$; thus, a decreasing $C_{U}$ could imply that the Uranium incorporation rate is slower than skeleton growth rate, and/or that Uranium clearance is involved. The latter possibility was tentatively addressed by us elsewhere [9]. In fact, Uranium concentration drops by a factor of 3 , approximately, from 0.75 ( $\mu$ g-U/g-bone) at $t=20 \mathrm{~d}$ to 0.2 ( $\mu$ g-U/g-bone) at $t=70 \mathrm{~d}$.

Ducks-The ratio C(ducks)/C(broilers) plotted in the insert in Figure 2 reveals that Uranium incorporation in ducks, relative to broilers, increased steeply from 3 (observed in life-period-1) to 17 at the age of 65 days. Interestingly, the results of this study show that mature ducks incorporate on average ten times more Uranium than broilers; a puzzlingly finding indicating that duck affinity for Uranium is much higher in adult individuals and, proportionally, much higher than for Calcium.

Biokinetics issues as clearance and slower or faster Uranium incorporation rates could be appraised by means of residence times via a simple Two Compartments Biokinetics Approach for uptake.

\subsection{Uranium Uptake through Two Compartments}

Let one consider that $m_{0}$ milligrams of Uranium administered to the birds move to a first compartment (skeleton), and then to a second compartment (kidneys, for instance), but do not return back to compartment \# 1 (the excretion process). A more complete biokinetics approach using e.g. a Multiple Compartments Model, beyond the scope of this Discussion, is to be found in our earlier publications [19].

After an elapsed time $t$ (s) Uranium mass incorporated into compartment \# 1 is $m_{1}(\mathrm{t})$, and the incorporation rate, $r_{1}(\mathrm{mg} / \mathrm{s})$, is given by

$$
r_{1}=-\left(\lambda_{1}+\lambda\right) \cdot m_{1}
$$

where $\lambda\left(\mathrm{s}^{-1}\right)$ is the Uranium radioactive decay constant and $\lambda_{1}\left(\mathrm{~s}^{-1}\right)$ is the biological "disappearance" rate of Uranium from compartment \# 1.

Uranium disappearing in compartment \# 1 reappears in compartment \# 2. Likewise, if $m_{2}(\mathrm{t})$ is the Uranium mass in compartment \# 2, its accumulation rate, $r_{2}(\mathrm{mg} / \mathrm{s})$, is given by

$$
r_{2}=+\lambda_{1} \cdot m_{1}-\left(\lambda+\lambda_{2}\right) \cdot m_{2}
$$

where $\lambda_{2}\left(\mathrm{~s}^{-1}\right)$ is the biological removal rate of Uranium from compartment \# 2 .

Considering that $r_{1}$ and $r_{2}$ are time derivatives of $m_{1}$ and $m_{2}$, respectively, the differential Equations (2) and (3) provide straightforward solutions for $m_{1}$ and $m_{2}$ as, e.g.,

$$
m_{1}(t)=m_{0} \cdot \exp \left[-\left(\lambda_{1}+\lambda\right) t\right]
$$

Likewise, one deduces the residence times of Uranium in compartments \# 1 (skeleton) and \# 2 (kidneys), $t_{1}$ and $t_{2}$ respectively, and given by

$$
t_{1}=\left(\lambda_{1}+\lambda\right)^{-1}
$$

and

$$
t_{2}=\lambda_{1}\left[\left(\lambda_{1}+\lambda\right) \cdot\left(\lambda_{2}+\lambda\right)\right]^{-1}
$$


The radioactive decay constant is defined as $\lambda=\tau^{-1}$, where $\tau$ is the mean life of the radionuclide. In the case of Uranium the order of magnitude of $\tau$ is hundreds of millions of years which here, for estimate purposes, render $\lambda$ $\approx 0$ and residence times

$$
t_{1}=\lambda_{1}^{-1} \text { and } t_{2}=\lambda_{2}^{-1}
$$

In fact, residence time $t_{1}$ in this approach is the time by which $100 \%$ of the total ingested Uranium moves out of compartment \# 1 (bones), while $\ln 2 \cdot \lambda_{1}^{-1}=0.69 \cdot \lambda_{1}^{-1}=0.69 \cdot t_{1}$ is the time by which $50 \%$ of the total ingested Uranium disappears from the bones.

Results showing that mature ducks incorporate on average ten times more Uranium than broilers strongly would indicate that

$$
t_{1} \text { (ducks) } \gg t_{1} \text { (broilers) } \rightarrow \lambda_{1} \text { (ducks) } \ll \lambda_{1} \text { (broilers) }
$$

Since the parameter $\lambda_{1}$ is a measure of the Uranium clearance rate in bones (or, as defined above, the biological "disappearance" from compartment \# 1), the smaller $\lambda_{1}$ is, the bigger the retention of Uranium in bones. Thus, Uranium clearance rate in broilers is substantially higher than in ducks.

In fact, metabolic properties intended to retain calcium in bone, probably hinder the elimination of uranyl in the body of ducks. Differences in enzymes and transport proteins playing a role in cellular calcium are likely to affect retention and elimination of uranyl in the body of birds; indicating that future studies in comparative biochemistry between the two groups can be explored in the discovery of new forms of metabolic elimination of uranyl, an issue high on the agenda of radiation protection.

\section{Conclusions}

1) The amount of Uranium present in bones and the bone masses of neonatal and young broilers increases at the same rate, indicating that $\mathrm{U}$ and Ca qualitatively follow the same metabolic pathway.

2) Mature ducks incorporate on average ten times more Uranium than broilers.

3) Conclusion \# 2 and a two compartments biokinetics approach suggest that Uranium clearance rate in broilers is much higher than in ducks.

4) Conclusion \# 3 supports the possibility that metabolic characteristics favoring Calcium retention in bone may hinder the elimination of Uranium in ducks.

5) Overall, all these conclusions point to the need for future comparative biochemistry studies between Galliformes and Anseriformes.

\section{References}

[1] Arruda-Neto, J.D.T., Tavares, M.V. and Filadelfo, M. (1997) Concentrations of Uranium in Animal Feed Supplements: Measurements and Dose Estimates. Journal of Radioanalytical and Nuclear Chemistry, 221, 97-104. http://dx.doi.org/10.1007/BF02035249

[2] Junqueira, O.M., Knoop, R. and Sakomura N.K. (1993) Meat and Bone Meal and Dicalcium Phosphate as Phosphorus Sources in Broilers Diet. Poultry Science, 72, 123.

[3] Lima, F.R., Mendonça Jr., C.X., Alvarez, J.C., Ratti, G., Lenharo, S.L.R., Kahn, H. and Garzillo, J.M.F. (1995) Chemical and Physical Evaluations of Commercial Dicalcium Phosphates as Sources of Phosphorus in Animal Nutrition. Poultry Science, 74, 1659-1670. http://dx.doi.org/10.3382/ps.0741659

[4] Sebastian, S., Touchburn, S.P., Chavez, E.R. and Lagué, P.C. (1996) Efficacy of Supplemental Microbial Phytase at Different Dietary Calcium Levels on Growth Performance and Mineral Utilization of Broiler Chickens. Poultry Science, 75, 1516-1523. http://dx.doi.org/10.3382/ps.0751516

[5] Tandon, L., Iyengar, G.V. and Parr, R.M. (1998) A Review of Radiologically Important Trace Elements in Human Bones. Applied Radiation and Isotopes, 49, 903-910. http://dx.doi.org/10.1016/S0969-8043(97)10102-6

[6] ICRP (1995) Age Dependent Doses to Members of the Public from Intake of Radionuclides: Part 3. Annals of the ICRP, 25.

[7] Legget, R.W. and Harrison, J.D. (1995) Fractional Absorption of Ingested Uranium in Humans. Health Physics, 68, 484-498. http://dx.doi.org/10.1097/00004032-199504000-00005

[8] Karpas, Z., Sorber, A., Elish, E., Kol, R., Roiz, Y., Marko, R., et al. (1998) Uptake of Ingested Uranium after Low “Acute Intake”. Health Physics, 74, 337-345. http://dx.doi.org/10.1097/00004032-199803000-00006 
[9] Arruda-Neto, J.D.T., Cestari, A.C., Nogueira, G.P., et al. (2005) Metabolical Aspects Associated with Incorporation and Clearance of Uranium by Broilers-Case Study and a Biophysical Approach. International Journal of Poultry Science, 4, 511-517. http://www.pjbs.org/ijps.htm http://dx.doi.org/10.3923/ijps.2005.511.517

[10] Woakes, A.J. and Butler, P.J. (1986) Respiratory, Circulatory and Metabolic Adjustments during Swimming in the Tufted Duck, Aythya fuugula. Journal of Experimental Biology, 120, 215-231.

[11] McNab, B.K. (1988) Food Habits and the Basal Rate of Metabolism in Birds. Oecologia, 77, 343-349. http://dx.doi.org/10.1007/BF00378040

[12] Bennett, P. and Harvey, P. (1987) Active and Resting Metabolism in Birds: Allometry, Phylogeny and Ecology. Journal of Zoology, 213, 327-344. http://dx.doi.org/10.1111/j.1469-7998.1987.tb03708.x

[13] Mairbaurl, H. (1994) Red Blood Cell Function in Hypoxia at Altitude Exercise. International Journal of Sports Medicine, 15, 51-63. http://dx.doi.org/10.1055/s-2007-1021020

[14] Weber, R.E. (1995) Hemoglobin Adaptation to Hypoxia and Altitude-The Phylogenetic Perspective. In: Sutton, J.R., Houston, C.S. and Coates, G., Eds., Hypoxia and the Brain, Queen City Printers, Burlington, 31-44.

[15] National Research Council (1994) Nutrient Requirements of Poultry: Ninth Revised Edition, 1994. The National Academies Press, Washington DC.

[16] De Soete, D., Gijbels, R. and Hoste, J. (1972) Neutron Activation Analysis. Wiley-Interscience, London, 835 p.

[17] Kulef, I. and Kostadivov, K. (1981) Epihtermal Neutron Activation Analysis of Uranium by Neptunium-239 Using High Resolution Gamma-Spectrometry. Journal of Radioanalytical Chemistry, 63, 397-404. http://dx.doi.org/10.1007/BF02522224

[18] Caria, M. (2000) Measurement Analysis. Imperial College Press, London.

[19] Garcia, F., Barioni, A., Arruda-Neto, J.D.T., Deppman, A., Millian, F., Mesa, J. and Rodriguez, O. (2006) Uranium Levels in the Diet of São Paulo City Residents. Environment International, 32, 697-703. http://dx.doi.org/10.1016/j.envint.2006.03.005 
Scientific Research Publishing (SCIRP) is one of the largest Open Access journal publishers. It is currently publishing more than 200 open access, online, peer-reviewed journals covering a wide range of academic disciplines. SCIRP serves the worldwide academic communities and contributes to the progress and application of science with its publication.

Other selected journals from SCIRP are listed as below. Submit your manuscript to us via either submit@scirp.org or Online Submission Portal.
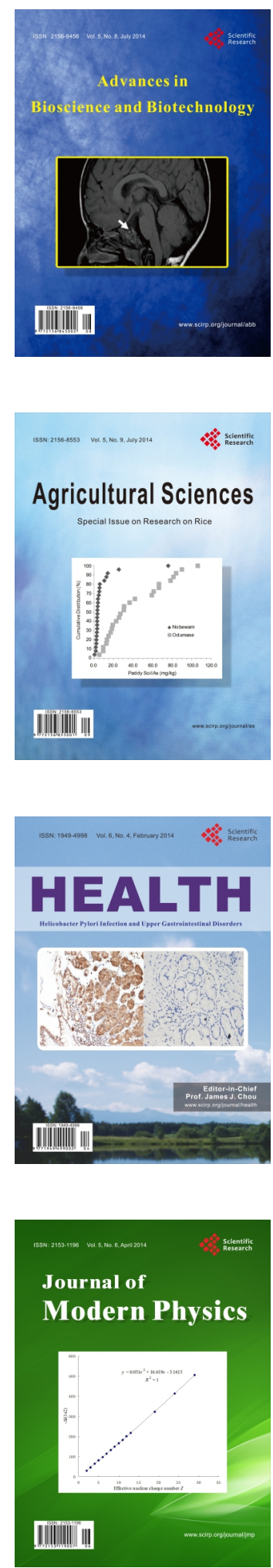
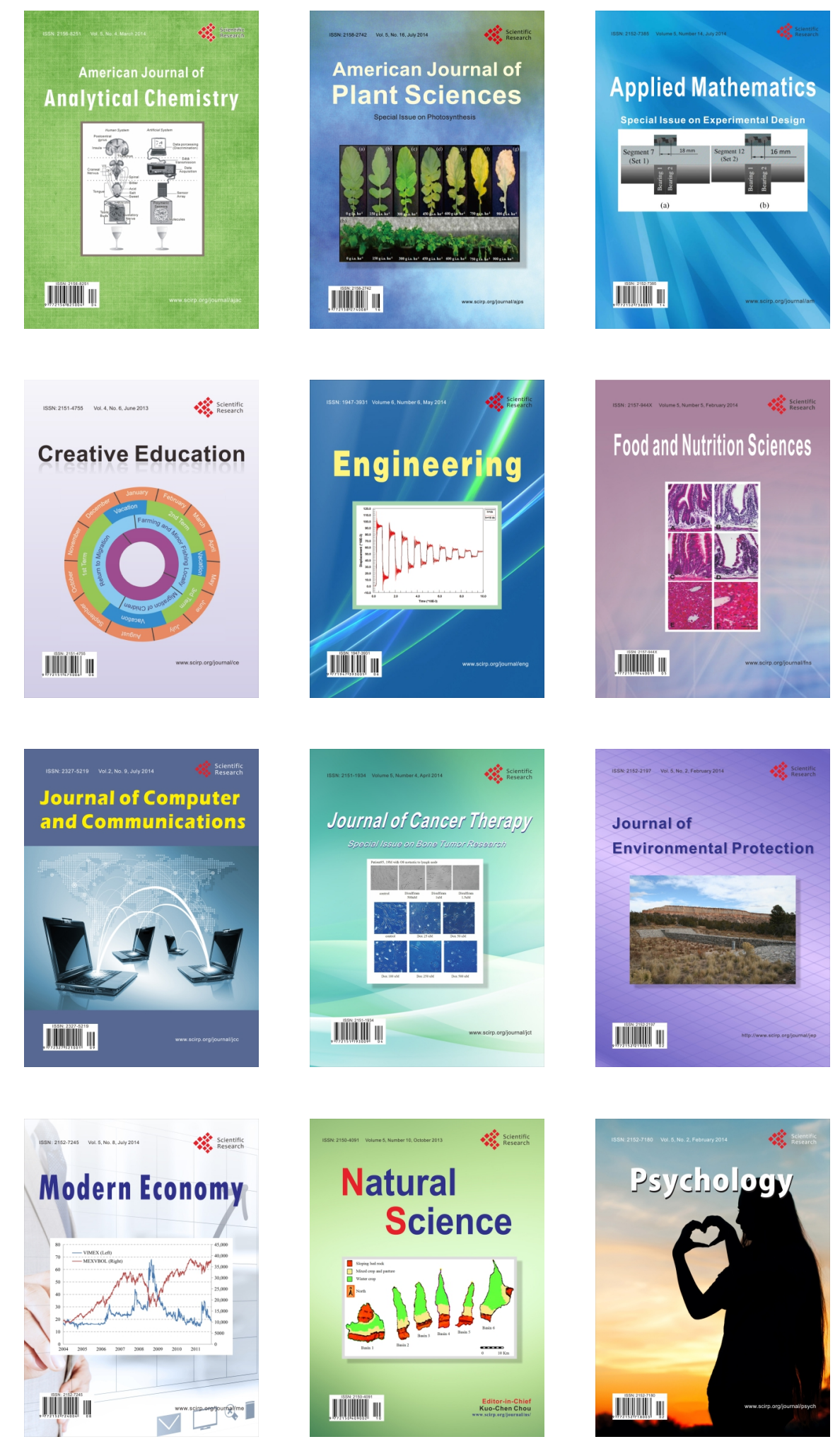